ARTIGOS

\section{ANÁLISE MULTIDIMENSIONAL DA SATISFAÇÃO NO TRABALHO NA COOPERATIVA DE GERAÇÃO E DISTRIBUIÇÃO DE ENERGIA DAS MISSÕES - CERMISSÕES DE CAIBATÉ-RS}

\section{RESUMO}

O objetivo deste artigo é identificar os índices de satisfação no trabalho apresentado pelos colaboradores da Cooperativa de Geração e Distribuição de Energia das Missões-CERMISSÕES, sob os aspectos de satisfação com os colegas de trabalho, salário, chefia, natureza do trabalho e promoções. Trata-se de uma pesquisa descritiva tipo survey, com abordagem quantitativa e qualitativa, tendo por base uma amostra aleatória por conveniência com 60 colaboradores do centro administrativo da CERMISSÕES, representando cerca de $30 \%$ do quadro funcional. Para realizar as análises e a interpretação dos dados quantitativos, foi utilizado o instrumento de pesquisa Escala de Satisfação no Trabalho (EST) de Siqueira (2008). Os resultados obtidos revelaram que os respondentes da pesquisa estão satisfeitos em todas as dimensões da satisfação no trabalho. No entanto, conforme a análise realizada, alguns itens obtiveram resultados de satisfação abaixo da média geral da respectiva dimensão.

Palavras-chave: Gestão de Pessoas. Comportamento Organizacional. Satisfação no Trabalho.

\section{INTRODUÇÃO}

A satisfação é um fator de suma importância para todos os seres humanos tanto na vida pessoal quanto no ambiente de trabalho. Com o passar dos anos, esse fator começou a ser o foco de vários estudos e pesquisas em todas as partes do mundo, pois descobriu tratar-se de uma situação que pode representar o sucesso ou o fracasso das organizações.

A forte concorrência que existe atualmente entre empresas faz que os gestores se preparem para os desafios que surgirão, por exemplo, o surgimento de tecnologias envolvendo novas formas de trabalho, os altos e baixos da economia e, principalmente, as variáveis que compõem os estudos sobre o Comportamento Organizacional, como o clima, a liderança, a satisfação, a motivação, os grupos de trabalho, o relacionamento interpessoal, o feedback, entre outros. 
O estudo teve como finalidade identificar quais são os índices de satisfação no trabalho apresentado pelos colaboradores da Cooperativa de Geração e Distribuição de Energia das Missões- CERMISSÕES, sob os aspectos de satisfação com os colegas de trabalho, salário, chefia, natureza do trabalho e promoções.

O estudo é relevante, visto que saber administrar pessoas pode representar a grande chave para o sucesso de uma empresa, pois cada pessoa é única com seu perfil, sua cultura e seus valores. Portanto, é necessário um estudo comportamental a fim de identificar o perfil profissional e pessoal de cada indivíduo, com o intuito de motivar todos os colaboradores, podendo ser este o diferencial competitivo de uma organização.

Os resultados do estudo são apresentados em quatro partes além desta introdução. A revisão da literatura trata sobre satisfação no trabalho. $\mathrm{Na}$ segunda parte, são apresentados os procedimentos metodológicos do estudo empírico. Na terceira e na quarta parte, constam os dados empíricos e as análises, bem como as conclusões.

\section{REVISÃO DA LITERATURA}

O termo satisfação no trabalho, na visão de Robbins (2005, p. 67), "se refere à atitude geral de uma pessoa em relação ao trabalho que realiza." $\mathrm{O}$ autor destaca ainda que o trabalho envolve muitas situações além das atividades óbvias do dia a dia, podendo citar a convivência com colegas e superiores, adaptação às políticas organizacionais, alcance de padrões de desempenho e aceitação de condições de trabalho geralmente abaixo do ideal. O autor Spector (2012) complementa afirmando tratar-se de uma variável que mostra o sentimento do indivíduo em relação ao seu trabalho, considerando os fatores, como colegas, salário, natureza do trabalho e chefia.

A atitude de uma pessoa está diretamente ligada ao seu grau de satisfação no trabalho. A partir disso, Robbins (2005, p. 61) explica que "uma pessoa que tem um alto nível de satisfação com seu trabalho apresenta atitudes positivas em relação a ele, enquanto uma pessoa insatisfeita apresenta atitudes negativas." $\mathrm{O}$ autor também cita que a satisfação dos funcionários impacta diretamente na satisfação dos clientes, visto que funcionários satisfeitos parecem mais propensos a falar bem da organização, a ajudar os colegas e a ultrapassar as expectativas em relação ao seu trabalho.

Os estudos sobre a satisfação no trabalho podem produzir resultados positivos, negativos e neutros. Davis e Newstrom (1992, p. 130) alertam que, se esses estudos forem devidamente planejados e gerenciados, acarretarão uma série de vantagens importantes, como a satisfação global no trabalho, comunicação, melhora nas atitudes, identificação das necessidades de treinamento, vantagens para os sindicatos e uma maior eficácia no planejamento e implementação de mudanças.

Estudos de Almeida et al. (2016) com 519 policiais militares, por exemplo, identificaram o predomínio de insatisfação em relação às dimensões salário e as promoções na carreira, também houve indiferença (nem satisfação nem insatisfação) com relação à chefia e à natureza do trabalho. A dimensão que obteve satisfação foi com relação aos colegas de trabalho.

A satisfação no trabalho ocorre quando efetivamente a pessoa gosta da atividade que realiza, sendo considerada uma resposta atitudinal em relação ao quanto o trabalho lhe provém quanto a recompensas e a compensações, porém não necessariamente que elas sejam financeiras (SCOTT-LADD; TRAVAGLIONE; MARSHALL, 2006).

No entendimento de Wagner III e Hollenbeck (1999, p. 129), manter a satisfação de um colaborador não é uma tarefa fácil, é um trabalho que precisa ser desenvolvido junto a cada pessoa, e um esforço contínuo e diário pela parte da gerência. Ao longo dos anos, os funcionários vêm mudando suas atitudes, pois antigamente era comum ficar por décadas trabalhando na mesma empresa, hoje permanecem, em média, no máximo, cinco anos.

É papel dos gestores organizacionais gerir a satisfação no trabalho, portanto os autores Baldwin, Bommer e Rubin (2015) afirmam que aquele gestor organizacional eficaz dispõe atenção irrestrita à satisfação de seus 
trabalhadores, levando em consideração as consequências que ultrapassam o desempenho individual. Eles também citam que estudos recentes revelam que a fidelização dos clientes está associada a uma maior satisfação do trabalhador, também que a satisfação está relacionada a um maior envolvimento e motivação e a baixos índices de rotatividade. Portanto, é relevante observar que é necessário que os gestores entendam não somente se os indivíduos estão satisfeitos ou não, mas também a relevância de entender qual é a natureza da satisfação.

Para Spector (2002, p. 221), "a satisfação no trabalho é uma variável de atitude que reflete como uma pessoa se sente com relação ao trabalho de forma geral e em seus vários aspectos. Significa o quanto as pessoas gostam de seu trabalho." Para o autor, existem dois enfoques para o estudo da satisfação no trabalho. O enfoque global, que trata da satisfação como um sentimento único e geral em relação ao trabalho, e o enfoque de facetas, que abrange os diferentes aspectos do trabalho, como os salários, os supervisores, os colegas, condições de trabalho e a natureza do trabalho em si. No entendimento de Siqueira (2008, p. 259), a satisfação no trabalho abrange cinco dimensões: satisfação com os colegas, chefia, salário, natureza do trabalho e promoções.

Satisfação no trabalho representa a totalização do quanto o indivíduo que trabalha vivencia experiências prazerosas no contexto das organizações. Assim, todas as cinco dimensões de satisfação no trabalho compreendem um foco, uma fonte ou origem de tais experiências prazerosas. Identificar os níveis de satisfação significa avaliar o quanto os retornos oferecidos pela organização na forma de salários e promoções, a convivência com os colegas e com a chefia e a realização das atividades propiciam aos profissionais sentimentos gratificantes (SIQUEIRA, 2008, p. 267).

Baldwin, Bommer e Rubin (2015) afirmam que, por muito tempo, houve diversas discussões afirmando que o desempenho no trabalho deveria ser a maior causa de níveis altos de satisfação no trabalho, levando em conside- ração, por exemplo, que o indivíduo o qual tivesse um desempenho superior se sentiria mais feliz e, em consequência, seria mais satisfeito. No entanto, estudos mais contemporâneos, com escalas maiores, sugerem que, na maioria das vezes, é a satisfação do próprio trabalhador que ajuda a aumentar o desempenho. É possível também perceber que muitas intervenções das organizações não alcançaram sucesso devido ao fato de se basearem, basicamente, na premissa de que deixar os trabalhadores felizes seria a base para se obter sucesso.

$\mathrm{Na}$ visão dos autores, para que uma organização tenha os seus funcionários satisfeitos, tornam-se necessárias certas observações em pelo menos cinco situações: na relação com os colegas de trabalho, no sistema de remuneração, nas relações destes com a chefia, na própria tarefa em si e também no modo como realiza as promoções de seu pessoal.

\section{METODOLOGIA}

Visando a responder ao objetivo deste estudo, empreendeu-se um estudo de cunho quantitativo e qualitativo, descritivo, do tipo survey, os sujeitos foram selecionados tendo por base uma amostra aleatória por conveniência com 60 colaboradores do centro administrativo da Cooperativa de Geração e Distribuição de Energia das Missões - CERMISSÕES, representando cerca de $30 \%$ do quadro funcional da organização.

Para realizar a pesquisa, foi utilizada a escala de satisfação no trabalho, o instrumento construído e validado por Siqueira (2008), que contempla cinco dimensões relacionadas ao trabalho: satisfação com o salário (cinco itens), satisfação com os colegas de trabalho (cinco itens), satisfação com a chefia (cinco itens), satisfação com as promoções (cinco itens) e satisfação com a natureza do trabalho (cinco itens), totalizando 25 itens que variam em uma escala likert de 7 pontos em que 1 (totalmente insatisfeito) a 7 (totalmente satisfeito). Os dados foram tabulados,

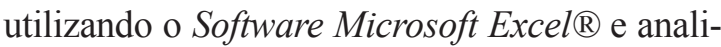
sados por meio do Software Statistica $10 \circledR$.

Devido ao fato de a EST ser uma medida 
multidimensional a qual contempla cinco dimensões, para cálculo do escore médio de cada dimensão, foi obtido a partir da soma dos valores assinalados em cada um dos itens que compõe cada dimensão posteriormente, foi dividido esse valor pelo número de itens da dimensão. Portanto, a soma sempre foi dividida por cinco, em que o resultado ficou entre 1 e 7 . Interpretam-se os resultados da seguinte maneira: valores entre 5 e 7 indicam satisfação, valores entre 4 e 4,9 representam indiferença (nem satisfeito, nem insatisfeito) e valores entre 1 e 3,9 sinalizam insatisfação (SIQUEIRA 2008).

\section{RESULTADOS}

O presente capítulo tem como objetivo expor os resultados encontrados na pesquisa de satisfação no trabalho dos colaboradores da Cooperativa de Geração e Distribuição de Energia das Missões - CERMISSÕES. Pesquisa composta por cinco dimensões, sendo satisfação com os colegas de trabalho, satisfação com o salário, satisfação com a chefia, satisfação em relação à natureza do trabalho e satisfação em relação às promoções.

\subsection{PERFIL DA AMOSTRA}

O perfil da amostra corresponde, em sua maioria, ao gênero masculino (65\%), faixa etária de 31 a 40 anos (40\%), estado civil casados $(55 \%)$, grau de escolaridade predomina o Ensino Médio (31\%), tempo de serviço na cooperativa de 3 a 10 anos $(43 \%)$ e tempo de serviço no cargo de 3 a 10 anos (46\%).

Tabela 1 - Caracterização geral do perfil da amostra

\begin{tabular}{c|c|c|c}
\hline Variáveis & Alternativas & Frequência & Percentual (\%) \\
\hline \multirow{2}{*}{ Gênero } & Feminino & 39 & $35 \%$ \\
& Masculino & 21 & $65 \%$ \\
\hline \multirow{3}{*}{ Faixa Etária } & 20 a 30 anos & 19 & $31 \%$ \\
& 31 a 40 anos & 24 & $40 \%$ \\
& Mais de 40 anos & 17 & $29 \%$ \\
\hline \multirow{2}{*}{ Estado Civil } & Casado & 33 & $55 \%$ \\
& Solteiro & 27 & $45 \%$ \\
\hline \multirow{5}{*}{ Grau de Escolaridade } & Ens. Fundamental & 15 & $25 \%$ \\
& Ens. Médio & 19 & $31 \%$ \\
& Superior incompleto & 4 & $8 \%$ \\
& Superior completo & 16 & $26 \%$ \\
Tempo de serviço da & Pós Graduação & 6 & $10 \%$ \\
\hline Cooperativa & Até 2 anos & 5 & $8 \%$ \\
& 3 a 10 anos & 26 & $43 \%$ \\
& 11 a 20 anos & 15 & $25 \%$ \\
Tempo de serviço no & Mais de 20 anos & 14 & $24 \%$ \\
\hline cargo & Até 2 anos & 23 & $39 \%$ \\
& 3 a 10 anos & 28 & $46 \%$ \\
& 11 a 20 anos & 5 & $9 \%$ \\
& Mais de 20 anos & 4 & $6 \%$ \\
\hline
\end{tabular}

Fonte: elaborado pelo autores (2017).

4.2 ANÁLISE DA ESCALA DE SATISFAÇÃO NO TRABALHO POR DIMENSÃO

Neste capítulo, apresentar-se-á a análise dos resultados obtidos por meio do questioná- rio EST. No questionário, cada dimensão da satisfação no trabalho foi composta por cinco questões, totalizando 25 questões aplicadas, as quais foram dispostas aleatoriamente. A análise detalhada utilizou como referência a média 
geral de cada dimensão, observando-se a variação de cada uma das cinco questões em torno dessa média. O Gráfico 1 apresenta a satisfação com os colegas de trabalho, em que a média da dimensão resultou 5,75, apontando satisfação dos funcionários.

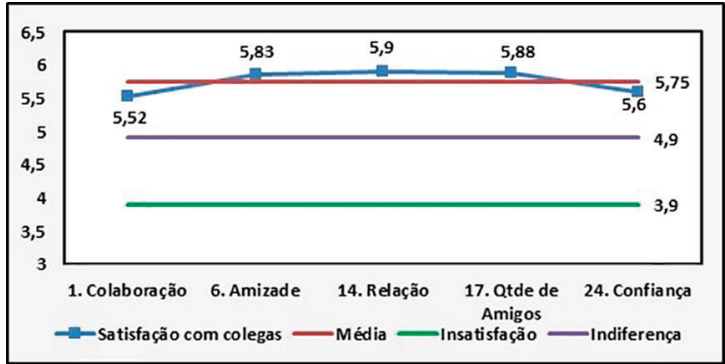

Gráfico 1 - Satisfação com colegas de trabalho Fonte: elaborado pelos autores (2017).

Apesar de todas as cinco questões que abrangem essa dimensão apresentarem resultados de satisfação, ou seja, acima de 4,9 , pode-se fazer outra análise observando a média geral da dimensão. Enquanto as questões "6", "14" e "17" apresentaram resultados acima da média, as questões "1" e "24" resultaram em valores abaixo da média.

A questão "1", a qual questiona a satisfação com o espírito de colaboração dos colegas, apresentou resultado de 5,52, ficando abaixo da média da dimensão. Esse menor índice de satisfação se deve, principalmente, ao fato de que muitos respondentes trabalham isoladamente em seus postos de trabalho, alguns com sua sala própria. Portanto, existe pouca interação com os demais colegas de empresa.

A satisfação com o tipo de amizade demonstrado pelos colegas foi abordada na questão " 6 " e apresentou um resultado de 5,83, acima da média da dimensão. Esse resultado se dá pelo fato de a maioria dos respondentes possuir um longo tempo de empresa, entre 3 e 10 anos, fortalecendo os laços de amizade entre os colegas de trabalho.

Pessoas que criam relações de amizade com seus colegas de trabalho se sentem mais motivadas, trazendo melhores resultados para a organização. Nesse contexto, Robbins (2005, p. 205) entende que "trabalhar em um ambiente que cultiva a cordialidade propicia união entre os envolvidos, e, no caso de uma organização, contribui com o crescimento do negócio, juntamente com o atingimento de objetivos do colaborador."

O resultado da questão "14" também ficou acima da média, questão que aborda a satisfação com a relação entre os colegas de trabalho, e apresentou um resultado de 5,9. Esse índice demonstra que existe uma boa relação entre os funcionários da CERMISSÕES, os quais trabalham em harmonia, em um ambiente com poucos conflitos e distorções.

No entendimento de Dubrin (2003, p. 246), o bom relacionamento entre os colegas de trabalho faz aumentar a coesão dos grupos, ou seja, um grupo que trabalha unido é capaz de alcançar a sinergia organizacional. Nesse sentido, cabe ressaltar que esse bom relacionamento trouxe bons resultados para a organização, sendo a Cooperativa em estudo uma referência nacional em relação à satisfação de seus clientes.

A questão de número "17", a exemplo das duas anteriores, apresentou resultado acima da média, obtendo o valor de 5,88. Nessa abordagem, foi questionada a satisfação com a quantidade de amigos entre os colegas de trabalho. Esse índice, indicando satisfação, deve-se ao fato de que muitos colegas de trabalho são também amigos fora da organização, existindo uma intensa relação de afinidade fora do ambiente de trabalho.

A satisfação com a confiança nos colegas de trabalho foi exposta na questão " 24 " e apresentou um resultado de 5,6, abaixo da média da dimensão. Uma justificativa para esse índice se dá pelo fato de que a maioria dos respondentes da pesquisa possui um cargo único, ocupado por somente uma ou duas pessoas.

Essa situação expõe uma menor confiança em um colega de outro setor que, por ventura, vier a substituir ou ajudar em determinada situação. Como o colega não está habituado a executar esse tipo de atividade, surge uma desconfiança por parte do funcionário substituído. Nesse sentido, o resultado dessa questão demonstrou que existe uma menor satisfação em 
relação à confiança nos colegas de trabalho.

O Gráfico 2 apresenta os resultados da pesquisa em relação à satisfação com o salário, em que a média da dimensão ficou acima de 4,9, resultando em 5,27, apontando satisfação dos funcionários.

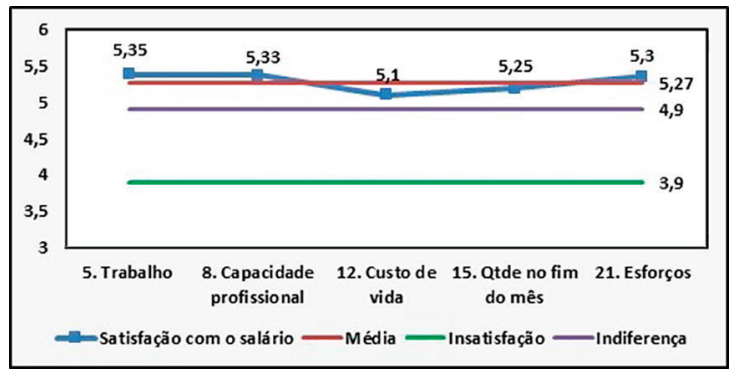

Gráfico 2 - Satisfação com o salário

Fonte: elaborado pelos autores (2017).

Observando o Gráfico 2, percebe-se que todas as cinco questões que compreendem essa dimensão apresentaram resultados de satisfação. Porém, pode-se fazer outra análise observando a média geral da dimensão. Enquanto as questões "5", "8" e "21" apresentaram resultados acima da média, as questões "12" e "15" resultaram em valores abaixo da média geral de satisfação com o salário.

A questão de número " 5 " examinou a satisfação do salário em relação ao quanto se trabalha e apresentou um resultado de 5,35, ficando acima da média geral dessa dimensão. Esse índice de satisfação se deve ao Programa de Participação nos Resultados adotado pela Cooperativa, o qual fornece uma remuneração extra para seus colaboradores. Outra justificativa se dá pelo fato de que a CERMISSÕES fornece uma série de benefícios, como auxílio médico, odontológico, vale alimentação, auxílio educação, dentre outros.

A satisfação com o salário em relação à capacidade profissional foi abordada na questão " 8 ", a qual teve um resultado de 5,33, ficando acima da média geral dessa dimensão. Uma justificativa para esse índice diz respeito ao fato de que a CERMISSÕES possui seu piso salarial regulado pelo sindicato da categoria (SITRACOO-
PER), obedecendo sempre às normas da CLT, no que diz respeito aos contratos de trabalho. Nesse sentido, todos os cargos têm seus níveis salariais fiscalizados, tendo isso como garantia.

Outra situação que merece ser destacada é o fato de que a Cooperativa em estudo também faz uma avaliação por desempenho, em que os colaboradores que apresentam melhores resultados possuem uma maior remuneração. Nesse sentido, os funcionários sentem-se motivados a buscar uma melhor qualificação e também melhorar seu desempenho. Cabe salientar também que a organização fornece auxílio para os colaboradores que desejam se qualificar, tanto no ensino técnico, quanto em graduação e pós-graduação.

A satisfação com o salário em relação ao custo de vida foi abordada na questão " 12 ", a qual apresentou um resultado de 5,1, ficando abaixo da média geral da dimensão. Uma explicação para esse menor índice se dá pelo atual contexto econômico nacional, permeado por indicadores inflacionários, principalmente nos itens essenciais, como os da cesta básica.

Também é preciso salientar os constantes reajustes em outros itens, como água, energia elétrica, transportes e taxas de saneamento, sem contar o alto volume de impostos que consome grande parte da renda do trabalhador brasileiro. Junto à desvalorização da moeda nacional, esses fatores ocasionam a diminuição do poder de compra do consumidor, consequentemente aumentando o custo de vida.

A questão número " 15 " questionou a satisfação em relação à quantidade de dinheiro recebido no final do mês, apresentando um resultado de 5,25, abaixo da média geral da dimensão. Um fator que retrata essa menor satisfação diz respeito à equidade dos salários, em que alguns funcionários que executam as mesmas atividades recebem remunerações diferentes. Como relatado anteriormente, a organização remunera seus funcionários com base no seu desempenho, o que causa as diferenças salariais. Por esse motivo, funcionários que ganham menos e executam os mesmos cargos se tornam menos satisfeitos.

A satisfação com o salário comparado 
aos esforços no trabalho foi abordada na questão " 21 ", obtendo um resultado de 5,3, acima da média geral da dimensão. Esse índice de satisfação se deve, assim como na questão "15", ao fato de que a CERMISSÕES remunera os seus funcionários conforme o desempenho de cada um, observando os seus esforços e se estes estão alcançando os resultados esperados. Nesse sentido, os colaboradores que se esforçam ganham uma remuneração maior do que os que se esforçam menos.

O Gráfico 3 apresenta os resultados da pesquisa em relação à satisfação com a chefia, em que a média da dimensão ficou acima de 4,9, resultando em 5,82, apontando satisfação dos funcionários. Além disso, essa dimensão apresentou o melhor resultado dentre as cinco que foram estudadas.

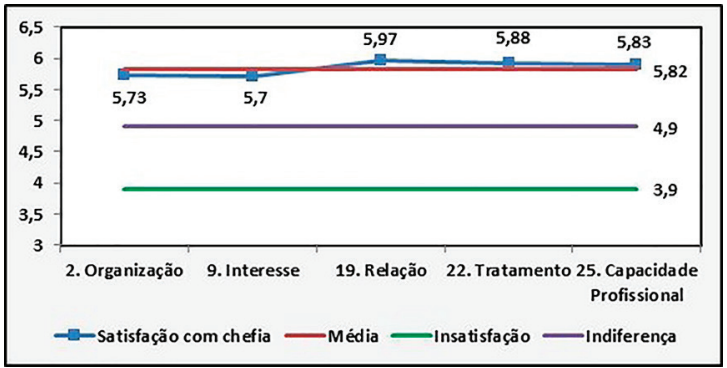

Gráfico 3 - Satisfação com a chefia

Fonte: elaborado pelos autores (2017).

Observando o Gráfico 3, percebe-se que todas as cinco questões que abrangem essa dimensão apresentaram resultados de satisfação. Enquanto as questões "19", "22" e "25" apresentaram resultados acima da média, as questões " 2 " e "9" resultaram em valores abaixo da média geral de satisfação com a chefia.

A questão número " 2 " questionou a satisfação com o modo como o chefe organiza o trabalho do setor e apresentou um resultado de 5,73, ficando abaixo da média geral da dimensão. A menor satisfação nesse quesito se deve principalmente ao fato de que, no entendimento dos respondentes da pesquisa, a chefia questionada se referia unicamente ao presidente da Cooperativa.

O fato de se relacionar ao presidente é que não cabe a ele organizar o trabalho de cada empregado, cabendo a cada indivíduo a responsabilidade de planejar e organizar as próprias tarefas do seu dia a dia. O líder, colocado em foco na pesquisa, faz o acompanhamento dos resultados gerais, não especificamente de cada colaborador. A esse fato se deve o menor índice de satisfação nessa questão.

A satisfação com o interesse do chefe pelo trabalho dos colaboradores foi abordada na questão "9" e apresentou um índice de 5,7, ficando abaixo da média geral da dimensão. Como foi citado anteriormente, o chefe citado na pesquisa não acompanha detalhadamente as atividades de cada funcionário.

De um modo geral, pode-se afirmar que a chefia se interessa sim pelo trabalho dos colaboradores, porém esse interesse não fica visível para os funcionários que estão executando suas atividades, visto que não existe um acompanhamento minucioso. Analisando esse aspecto, percebe-se a causa pela qual houve uma menor satisfação dos respondentes nessa questão.

A questão "19" abordou a satisfação em relação ao entendimento com o chefe e apresentou um resultado de 5,97, ficando acima da média geral dessa dimensão. Esse índice mostra que existe uma boa relação entre a chefia e seus colaboradores, aumentando o nível de confiança, resultando em um ambiente de trabalho mais tranquilo e favorável.

A satisfação com o tratamento recebido pela chefia foi abordada na questão " 22 " e apresentou um resultado de 5,88, ficando acima da média geral da dimensão. Esse índice mostra que existe um tratamento satisfatório da chefia com seus funcionários, tratando todos de forma justa e igualitária, mantendo a equidade nesse sentido.

Tratar bem seus funcionários se constitui como uma obrigação da liderança, visto que são estes que fazem que a organização atinja suas metas e objetivos. Atitudes justas por parte da liderança aumentam a confiança e proporcionam o engajamento de seus subordinados. Nessa visão, Robbins (2005, p. 280) destaca que "se você não vê justiça em seu chefe, nos procedimentos da empresa ou na sua política 
de remuneração, sua satisfação com o trabalho decai consideravelmente."

Por fim, a questão " 25 " abordou a satisfação em relação à capacidade profissional da chefia, a qual teve um resultado de 5,83, ficando acima da média geral da dimensão. Esse índice de satisfação retrata bem o profissionalismo da liderança na organização em estudo. O atual presidente da CERMISSÕES, o qual foi o foco da pesquisa nessa dimensão, realizou várias mudanças na Cooperativa desde que assumiu o seu cargo.

Exercendo a sua liderança desde 1988, quando assumiu o seu cargo, o atual presidente encontrou a Cooperativa em estado de falência, estando em péssima condição financeira e com mais de 600 funcionários. Como a situação da Cooperativa estava complicada, a maioria dos colaboradores se sentia com o emprego ameaçado, havia a desconfiança e o medo de ficar desempregado a qualquer momento.

Passados 28 anos de mandato, a Cooperativa conta hoje com cerca de 200 funcionários, havendo uma demanda de trabalho maior do que em outras épocas. Além disso, encontra-se em boa situação financeira e atualmente é a melhor distribuidora de energia elétrica do país, tendo conquistado esse prêmio nos anos de 2014, 2015 e 2016.

A transformação realizada nesse período traduz bem a satisfação dos funcionários com a capacidade profissional da chefia, visto que a organização se encontra em uma boa situação financeira, o que provoca, consequentemente, uma maior tranquilidade e confiança para os seus colaboradores, fazendo que estes trabalhem com tranquilidade e tenham a garantia de estabilidade em seus respectivos cargos.

Os resultados da pesquisa em relação à satisfação com a natureza do trabalho encontram-se no Gráfico 4. A média dessa dimensão resultou em 5,67, apontando satisfação dos funcionários.

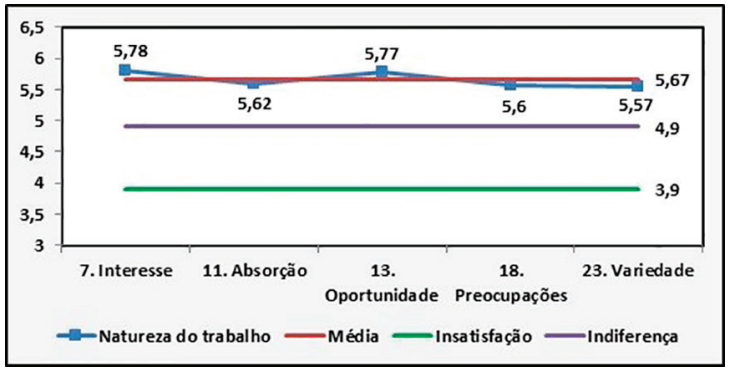

Gráfico 4 - Satisfação em relação à natureza do trabalho

Fonte: elaborado pelos autores (2017).

Observando o Gráfico 4, percebe-se que todas as cinco questões que abrangem essa dimensão apresentaram resultados de satisfação, ou seja, acima de 4,9. Porém, pode-se fazer outra análise observando a média geral da dimensão. Enquanto as questões "7" e "13" apresentaram resultados acima da média, as questões " 11 ", "18" e " 23 " resultaram em valores abaixo da média geral de satisfação com a natureza do trabalho.

Em relação à questão número “7”, a qual questionou a satisfação com o grau de interesse que as tarefas despertam, percebe-se que esta apresentou um resultado de 5,78, ficando acima da média geral da dimensão. Esse índice mostra que os funcionários da CERMISSÕES estão satisfeitos com as tarefas que estão desempenhando em seus cargos. Essa satisfação se deve, principalmente, às constantes tecnologias que são adquiridas pela Cooperativa.

A questão número "11" abordou a satisfação com a capacidade das tarefas de absorverem o trabalhador e apresentou um resultado de 5,62, ficando abaixo da média da dimensão. A menor satisfação nessa perspectiva ocorre pelo fato de que as atividades desempenhadas pela maioria dos respondentes da pesquisa requerem um alto índice de atenção e concentração, o que proporciona um desgaste psicológico em alguns profissionais.

A satisfação com a oportunidade de realizar esse tipo de trabalho foi contemplada na questão número "13" e obteve um resultado de 5,77, acima da média da dimensão. Como os respondentes da pesquisa trabalham no centro administrativo da Cooperativa, executam tare- 
fas que possuem uma maior responsabilidade e tomada de decisões. $\mathrm{O}$ fato de os respondentes ocuparem esses cargos gera uma maior satisfação nessa perspectiva.

Nesse sentido, o enriquecimento do cargo é citado por Dubrin (2003, p. 140) como a providência de tornar um cargo mais motivacional e gratificante ao acrescentar variedade, responsabilidade e tomada de decisões gerenciais. Para o autor, o enriquecimento do cargo dá aos empregados um sentido de propriedade, conscientização e responsabilidade por seu trabalho. "Em virtude de o enriquecimento do cargo ocasionar um trabalho mais estimulante, muitas vezes, esse fator aumenta a satisfação do empregado no cargo."

A satisfação com as preocupações exigidas pelo trabalho contempla a questão número "18" e apresentou um resultado de 5,6, abaixo da média geral da dimensão. Essa menor satisfação acontece pelo fato de que, como comentado na questão anterior, os respondentes executam atividades administrativas de grande responsabilidade na organização.

Essa maior responsabilidade na execução das tarefas tem como principal consequência a preocupação com o trabalho, visto que um eventual erro ou engano em determinada atividade poderá comprometer algum processo ou até mesmo os resultados da Cooperativa. Essa preocupação em executar as atividades com "erro zero" justifica o menor índice de satisfação nessa perspectiva.

A questão número " 23 ” abordou a satisfação com a quantidade de tarefas realizadas e apresentou um resultado de 5,57, abaixo da média da dimensão. Essa menor satisfação nessa perspectiva ocorre, principalmente, pelo fato de que os respondentes da pesquisa, em sua maioria, realizam apenas uma função na organização, não havendo rodízio de tarefas e consequentemente o trabalho torna-se repetitivo.

Os resultados da pesquisa em relação à satisfação com as promoções encontram-se no Gráfico 5. A média dessa dimensão resultou em 5,32, apontando satisfação dos funcionários.

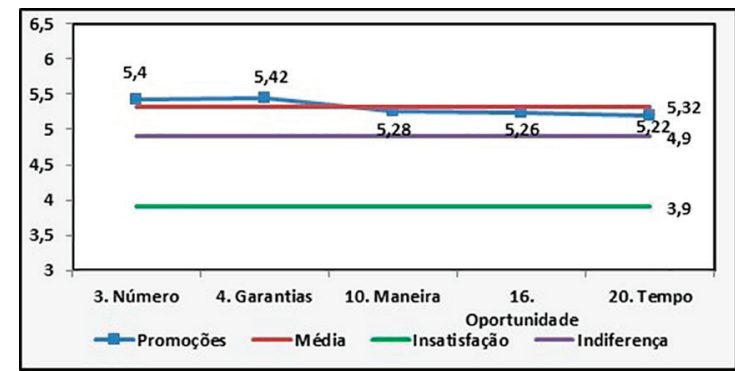

Gráfico 5 - Satisfação em relação às promoções Fonte: elaborado pelos autores (2017).

Observando o Gráfico 5, percebe-se que todas as cinco questões que envolvem essa dimensão apresentaram resultados de satisfação, ou seja, acima de 4,9. Enquanto as questões "3" e "4" apresentaram resultados acima da média, as questões " $10 "$, " $16 "$ e "20" resultaram em valores abaixo da média geral da satisfação em relação às promoções.

Em relação à questão número “3”, a qual abordou a satisfação com o número de vezes em que foi promovido, observa-se que esta apresentou um resultado de 5,4, ficando acima da média da dimensão. Esse alto índice de satisfação se justifica na medida em que se pode comparar o tempo de serviço dos funcionários na Cooperativa com o tempo de serviço no cargo.

Pode se observar que, em praticamente todos os níveis, existe uma notável correlação nesse sentido. Como exemplo, pode-se utilizar a faixa dos funcionários que possuem até 2 anos de empresa, os quais correspondem a $8 \%$ dos respondentes. Por outro lado, a faixa dos funcionários que estão até 2 anos no cargo corresponde a $39 \%$. Esses dados mostram que, pelo menos, $31 \%$ dos respondentes teve algum tipo de promoção nos últimos 2 anos.

A satisfação com as garantias oferecidas a que é promovido foi abordada na questão " 4 " e apresentou um resultado de 5,42, acima da média da dimensão. Esse índice de satisfação se deve, principalmente, à situação estável em que se encontra a CERMISSÕES, o que torna o ambiente mais tranquilo para os trabalhadores, gerando uma garantia de estabilidade para os indivíduos que recebem promoções e fortalecendo os planos de carreira. 
A questão número "10" contemplou a satisfação com a maneira com que são realizadas as promoções e apresentou um índice de 5,28, abaixo da média da dimensão. Esse resultado de satisfação abaixo da média se deve ao fato de que alguns colaboradores não concordam com o modo como esse processo é realizado na Cooperativa.

O que ocorre, na organização em estudo, são algumas situações que provocam divergências, como o fato de que algumas pessoas acreditam que existem alguns colegas que são beneficiados por ter algum grau de parentesco ou até mesmo uma maior afinidade com os trabalhadores que ocupam os cargos de chefia. Essa situação traria, supostamente, um beneficiamento no que diz respeito às promoções. Nesse sentido, alguns respondentes demonstraram insatisfação nessa perspectiva.

A satisfação com a oportunidade de ser promovido nessa empresa foi abordada na questão "16", apresentou um resultado de 5,26, ficando abaixo da média da dimensão. Esse menor índice de satisfação nesse quesito diz respeito ao fato de que um pequeno número de funcionários tem pouco acesso às oportunidades de crescimento, demonstrando total insatisfação nessa perspectiva. Isso ocorre, na maioria das vezes, pela falta de conhecimentos ou habilidades necessárias para que o trabalhador execute determinada função.

A questão de número "20" contemplou a satisfação com o tempo de espera para receber uma promoção e apresentou um resultado de 5,22, abaixo da média da dimensão. Esse índice menor de satisfação ocorre pelo fato de que alguns indivíduos possuem pouca paciência no que diz respeito ao tempo de espera, mostrando ansiedade e pressa em querer ser promovido.

\subsection{ANÁLISE DA ESCALA DE SATIS- FAÇÃO NO TRABALHO}

O Gráfico 6 apresenta a sistematização dos resultados da satisfação no trabalho, contendo as médias gerais das dimensões. Pode-se observar que o resultado foi de satisfação em todas as cinco dimensões, visto que todos os resultados ficaram acima de 4,9. Consequentemente, a média geral resultou em 5,57, o que indica a satisfação no trabalho.

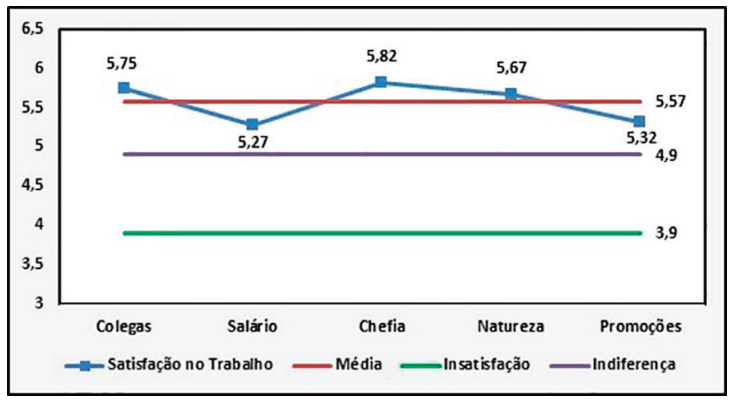

Gráfico 6 - Sistematização dos resultados da Satisfação no Trabalho

Fonte: elaborado pelos autores (2017).

Sob outra perspectiva, utilizando a média geral como referência, percebe-se que as dimensões satisfação com colegas, satisfação com a chefia e satisfação com a natureza do trabalho apresentaram resultados acima da média geral, valores estes de 5,75, 5,82 e 5,67, respectivamente. Em contrapartida, as dimensões satisfação com o salário e satisfação em relação às promoções apresentaram resultados abaixo da média geral, valores estes de 5,27 e 5,32, respectivamente.

A satisfação com os colegas de trabalho apresentou um resultado de 5,75, resultado esse que representa a satisfação. Além disso, a dimensão está acima da média geral de satisfação no trabalho. Observando o resultado da pesquisa, pode-se afirmar que existe, na organização CERMISSÕES, satisfação em relação ao espírito de equipe, colaboração, relacionamento interpessoal, amizade e confiança entre seus colegas de trabalho.

Em outra dimensão, analisando a satisfação com o salário, percebe-se, por meio do gráfico 6 , que essa dimensão apresentou um resultado de 5,27, indicando satisfação. Porém, a média dessa dimensão ficou abaixo da média geral de satisfação no trabalho.

Alguns fatores explicam a menor satisfação nessa dimensão, como o atual contexto econômico brasileiro, o que faz aumentar o custo de vida; o descontentamento de alguns colabo- 
radores, que acreditam não ter uma remuneração condizente com sua qualificação profissional e também o fato de que alguns funcionários estão insatisfeitos com a remuneração em comparação com os esforços realizados no trabalho.

Em relação à satisfação com a chefia, essa dimensão apresentou um resultado de 5,82, indicando satisfação. Além disso, apresentou o melhor resultado dentre as cinco dimensões estudadas. Esse resultado positivo se dá, principalmente, pela boa relação existente entre os funcionários e a chefia.

Outra dimensão que apresentou um resultado de satisfação diz respeito à natureza do trabalho. Essa perspectiva apresentou um resultado de 5,67 , ficando acima da média geral. Esse resultado demonstra satisfação dos funcionários da CERMISSÕES com as tarefas exercidas na Cooperativa e as preocupações exigidas por estas.

A última perspectiva estudada foi a satisfação com as promoções, a qual teve um resultado de 5,32, indicando satisfação. Apesar disso, esse resultado ficou abaixo da média geral de satisfação no trabalho. Essa satisfação abaixo da média se deve, principalmente, ao tempo de espera, à oportunidade e à maneira como são realizadas as promoções.

\section{CONSIDERAÇÕES FINAIS}

Apesar de todas as dimensões terem apresentado um resultado de satisfação no trabalho, forma obtidos diferentes resultados em cada perspectiva. Pelos resultados apresentados, percebe-se que todas as 25 questões que contemplaram o questionário aplicado no presente estudo apresentaram resultados de satisfação no trabalho. No entanto, alguns itens obtiveram resultados de satisfação abaixo da média geral da respectiva dimensão. A partir disso, propõem-se algumas ações que poderão ser utilizadas pela Cooperativa.

A primeira dessas propostas diz respeito ao job rotation, que também pode ser definido como rotação de cargos, o qual Chiavenato (2010) define como a movimentação das pessoas em várias posições na organização no esforço de expandir suas habilidades, conhecimentos e capacidades. A rotação de cargos, na dimensão da satisfação com os colegas, traria melhores resultados no sentido de maior interação entre os colaboradores, fortalecendo o espírito de colaboração entre eles, visto que a maioria dos colaboradores teria capacidade para executar as diversas funções que lhes fossem designadas.

$\mathrm{Na}$ dimensão que corresponde à satisfação com a natureza do trabalho, o rodízio de cargos também seria de suma importância, visto que, além de aumentar a variedade de tarefas realizadas, traria resultados no sentido de minimizar os impactos psicológicos dos colaboradores motivados pelo excesso de rotina, principalmente das atividades mais desgastantes e que requerem um grau maior de atenção.

A implantação da rotação de cargos também proporcionaria um maior índice de satisfação no trabalho no que diz respeito às promoções, ao passo que os colaboradores da organização estariam em constantes trocas de funções, o que minimizaria as insatisfações causadas pelo tempo de espera e pela oportunidade de receber uma promoção.

Outra proposta que traria resultados significativos para a Cooperativa em estudo seria a implantação de um plano de cargos e salários. Esse plano teria como objetivo proporcionar e estabelecer uma estrutura equitativa e justa na Cooperativa, tanto no nível de salários quanto no nível de cargos. No nível salarial, o salário de cada cargo deve ser baseado nos conhecimentos exigidos pela função, pela complexidade das atividades desenvolvidas, pelas responsabilidades com execução de tarefas e pela apresentação dos resultados específicos esperados do cargo. Os salários devem ser estabelecidos de forma a serem competitivos quando comparados com os padrões de mercado, o que permitirá atrair e reter profissionais de bom desempenho.

Quando implementado na organização, todos estarão a par de quais competências precisarão ter para ocupar determinado cargo ou atingir a faixa salarial adequada. Portanto, o 
plano de cargos e salários estimulará o autogerenciamento do plano de carreira, remuneração clara e transparente, disponibilizando parâmetros para o desenvolvimento profissional, resultando numa maior satisfação do funcionário.

A pesquisa demonstrou que os colaboradores da organização apresentam satisfação no trabalho em todas as suas dimensões. Essa satisfação dos funcionários comprova o bom atendimento e a qualidade dos serviços ofertados aos clientes/associados, o que rendeu à empresa CERMISSÕES, por três anos consecutivos, o prêmio IASC - Índice ANEEL de Satisfação do Consumidor. Nesse sentido, o estudo demonstrou que a organização investe em seus colaboradores, mantendo-se como referência nacional no setor de geração e distribuição de energia elétrica.

Quanto às limitações da pesquisa, destaca-se que não é possível generalizar os resultados aos demais profissionais do Estado e do Brasil, em função das diferenças de estrutura e cultura da organização e dos colaboradores. Sugere-se que esse mesmo método de pesquisa se realize sob um viés longitudinal, pois essa abordagem possibilita monitorar o desenvolvimento e a mudança no grau de satisfação no trabalho. Também que seja realizado um estudo buscando identificar os antecedentes para a satisfação no trabalho.

\section{MULTIDIMENSIONAL ANALYSIS OF SATISFACTION IN WORK IN THE COOPERATIVE OF GENERATION \\ AND ENERGY DISTRIBUTION OF MISSÕES (CERMISSÕES) OF CAIBATÉ-RS}

\begin{abstract}
The objective of this article is to identify the satisfaction indexes presented by the employees of the Cooperative of Energy Generation and Distribution of Missões - CERMISSÕES, under the aspects of satisfaction with co-workers, salary, management, nature of work and promotions. It is a descriptive survey, with a
\end{abstract}

quantitative and qualitative approach, based on a random sample for convenience with $60 \mathrm{em}-$ ployees of the CERMISSÕES administrative center; this number represents about $30 \%$ of the organization's staff. In order to perform the analysis and interpretation of the quantitative data, the research instrument Scale of Work Satisfaction (EST) was used, adapted from the model of Siqueira (2008). The results obtained revealed that respondents are satisfied in all dimensions of job satisfaction. However, according to the analysis performed, some items obtained satisfaction results below the general average of the respective dimension.

Keywords: People management. Organizational behavior. Job Satisfaction.

\section{ANÁLISIS MULTIDIMENSIONAL DE LA SATISFACCIÓN EN EL TRABAJO EN LA COOPERATIVA DE GENERACIÓN Y DISTRIBUCIÓN DE ENERGÍA DE MISSÕES (CERMISSÕES) DE CAIBATÉ - RS}

\section{RESUMEN}

El objetivo de este artículo es de identificar los índices de satisfacción en el trabajo presentados por los empleados de la Cooperativa de Generación y Distribución de Energía de Missões - CERMISSÕES, bajo los aspectos de satisfacción con los colegas de trabajo, el salario, la jefatura, la naturaleza del trabajo y las promociones. Se trata de una investigación descriptiva tipo survey, con un abordaje cuantitativa y cualitativa, teniendo por base una muestra aleatoria por conveniencia con 60 empleados del centro administrativo de CERMISSÕES, lo que representa alrededor de $30 \%$ del cuadro de funcionarios. Para realizar el análisis y la interpretación de los datos cuantitativos se utilizó el instrumento de investigación Escala de Satisfacción en el Trabajo (EST), de Siqueira (2008). Los resultados revelaron que los que contestaron el survey están satisfechos en todas las dimensiones de satisfacción en el trabajo, 
aunque, de acuerdo con el análisis, algunos puntos obtuvieron resultados de satisfacción debajo de la media general de la respectiva dimensión.

Palabras-clave: Gestión de personas. Comportamiento Organizacional. Satisfacción en el Trabajo.

ANALYSE
MULTIDIMENSIONNELLE DE LA
SATISFACTION DANS LE TRAVAIL
DANS LA COOPERATIVE DE
GENERATION ET DISTRIBUTION
D'ENERGIE DE MISSÕES
(CERMISSÕES) A CAIBATÉ-RS

\section{RESUME}

L'objectif de cet article est d'identifier les indices de satisfaction dans le travail présentés par les employés de la Coopérative de génération et distribution d'énergie de Missões - CERMISSÕES, sous les aspects de satisfaction avec le collègues de travail, les salaires, la direction, la nature du travail et les promotions. C'est une recherche descriptive du type survey, avec un abordage quantitatif et qualitatif, ayant pour base um échantillon aléatoire par convenance avec 60 collaborateurs du centre administratif de CERMISSÕES, ce qui représente près de $30 \%$ des quadres de fonctionnaires. Pour réaliser les analyses et l'interprétation des données quantitatives nous avons utilisé l'instrument de recherche Echelle de satisfaction dans le travail (ETS), de Siqueira (2008). Les résultats obtenus ont révélé que ceux qui ont répondu à l'enquête sont satisfaits dans toutes les dimensions de satisfaction dans le travail. Néanmoins, selon l'analyse réalisée, certains points ont eu des résultats de satisfaction en dessous de la moyenne générale de la dimension respective.

Mots-clés: Gestion de Personnes. Comportement Organisationnel. Satisfaction dans le Travail.

\section{REFERÊNCIAS}

ALMEIDA, D. M. et al. Satisfação no trabalho dos policiais militares do Rio Grande do Sul: um estudo quantitativo. Revista Psicologia: Ciência e Profissão, Brasília, v. 36, n. 4, p. 801-815, out./dez. 2016.

BALDWIN, T. T.; BOMMER, W. H.; RUBIN, R. S. Gerenciando o comportamento organizacional: o que gestores eficazes sabem e fazem. Tradução Edson Furmankiewicz. 2. ed. Rio de Janeiro: Elsevier, 2015.

CHIAVENATO, Idalberto. Comportamento organizacional. 2. ed. Rio de Janeiro: Elsevier, 2010 .

DAVIS, K.; NEWSTROM, J. W. Comportamento humano no trabalho: uma abordagem psicológica. Tradução de Cecília Bergamini e Roberto Coda. São Paulo: Pioneira Thompson Learning, 1992.

DUBRIN, Andrew J. Fundamentos do comportamento organizacional. Tradução de James Cook e Martha Leal. Revisão técnica de Reinaldo O. da Silva. 2. ed. São Paulo: Pioneira Thomson Learning, 2003.

ROBBINS, S. P. Comportamento organizacional. Tradução técnica Reynaldo Marcondes. 11. ed. São Paulo: Pearson Prentice Hall, 2005.

SCOTT-LADD, B.; TRAVAGLIONE, A.; MARSHALL, V. Causal inferences between participation in decision making, task attributes, work effort, rewards, job satisfaction and commitment. Leadership \& Organization Development Journal, n. 27, v. 5, p. 399-414, 2006.

SIQUEIRA, M. M. M. (Org.). Medidas do comportamento organizacional: ferramentas de diagnóstico e gestão. Porto Alegre: Artmed, 2008. 
SPECTOR, E. P. Psicologia nas organizações.

Tradução de Solange Aparecida Visconte. Revisão técnica de Maria José Tonelli. São Paulo: Saraiva, 2002.

. Psicologia nas organizações. 4. ed. São Paulo: Saraiva, 2012.

WAGNER III, J. A.; HOLLENBECK, J. R. Comportamento organizacional: criando vantagem competitiva. Tradução Cid Knipel Moreira. Revisão técnica Laura Zaccarelli. São Paulo: Saraiva, 1999. 